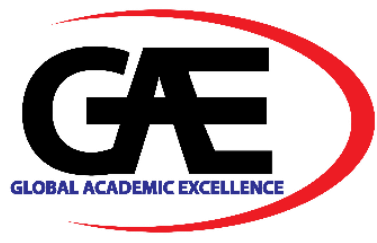

\title{
STUDENTS' PERSPECTIVES IN STUDYING MATHEMATICS SUBJECT THROUGH E-LEARNING TOOLS AT FOUNDATION EDUCATION LEVEL
}

\author{
Che Haziqah Che Hussin ${ }^{1}$, Nurliyana Juhan ${ }^{2 *}$, Suriana Lasaraiya ${ }^{3}$, Ayu Afiqah Nasrullah ${ }^{4}$ \\ 1 Preparatory Centre for Science and Technology, Universiti Malaysia Sabah, Malaysia \\ Email: haziqah@ums.edu.my \\ 2 Preparatory Centre for Science and Technology, Universiti Malaysia Sabah, Malaysia \\ Email: liyana87@ums.edu.my \\ 3 Preparatory Centre for Science and Technology, Universiti Malaysia Sabah, Malaysia \\ Email:suriana@ums.edu.my \\ 4 Preparatory Centre for Science and Technology, Universiti Malaysia Sabah, Malaysia \\ Email: ayu.afiqah@ums.edu.my \\ Corresponding Author
}

Article Info:

Article history:

Received date: 11.09 .2021

Revised date: 10.10 .2021

Accepted date: 15.11 .2021

Published date: 30.11 .2021

To cite this document:

Hussin, C. H. C., Juhan, N., Lasaraiya, S., \& Nasrullah, A. A. (2021). Students' Perspectives In Studying Mathematics Subject Through ELearning Tools At Foundation Education Level. Journal of Information System and Technology Management, 6 (23), 108-117.

DOI: $10.35631 / J I S T M .623004$

This work is licensed under CC BY 4.0

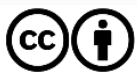

Abstract:

The aim of the study was to find out how students preferred using asynchronous and synchronous e-learning tools. Asynchronous learning occurs when there is no predetermined time for it to take place. Learners can learn whenever and wherever they want, and they can take their time to learn what they need to know. Synchronous e-learning is characterized by structured and time-bound activities delivered via web conferencing and chatting. At the Preparatory Centre for Science and Technology, Universiti Malaysia Sabah (PCST, UMS) lecturers could conduct synchronous or asynchronous due to MCO which was enforced on March 18, 2020. As a result, this study was done to examine the impact of several learning styles on foundation UMS students during the COVID-19 crisis, including synchronous and asynchronous. The quantitative data analysis of research will be presented in this study. Microsoft Excel was used for data analysis. The male and female students' opinions were compared using an independent sample t-test. Additionally, the responses of students to various aspects of e-learning were represented using descriptive statistics. The findings found a significant difference in students' perceptions of the efficacy of asynchronous e-learning activities. Female students' responses show that they found asynchronous is more effective than male students at the foundation education level. Students were found to have a greater interest in asynchronous and blended learning activities. 


\section{Introduction}

The fast spread of COVID-19 has sparked worldwide challenges. The Malaysian government declared the closing of educational institutions as a preventative measure to control the outbreak during the implementation of the Movement Control Order (MCO). This situation has transformed the educational environment in Malaysia, posing new challenges for educators and students. They must adapt to the changing expectations and norms. To ensure that educational activities can proceed, new methods in the teaching and learning (T\&L) process must be adopted. As a result, online learning is no longer an option, but rather an obligation. (Libasin et al., 2021)

Asynchronous Online Learning (OL-async) and Synchronous Online Learning (OL-sync are two types of online learning that educators can use to deliver teaching. Singh \& Thurman, (2019) defined online learning (OL) as synchronous or asynchronous learning approaches using various devices such as smartphones and computers with internet support. The synchronous approach indicates that the learning process takes place in real-time, requiring both the instructor and the students to be present at the same time, even if they are in separate locations. On the other hand, the asynchronous approach does not necessitate real-time engagement. The adoption of online learning implies that the learning process can take place anywhere there is internet access and the use of specific devices (Libasin et al., 2021). It is advised to use synchronous support tools when conducting remote learning such as Google Meet or Cisco Webex in places with stable and high-speed internet connectivity. However, in locations where internet access is unreliable, asynchronous assistance technologies such as the Smartv3ums platform can be used instead of remote learning. T\&L can also be carried out by recording videos and audio and then sharing them with students via YouTube and the Smartv3ums platform.

Several studies have explored how different learning styles affect students' academic performance and educational perceptions. Duncan et al., (2012) investigated the relation between MBA students' performance and their participation in synchronous and asynchronous virtual learning environments. In comparison to asynchronous interaction, they found that the quality and quantity of student participation in synchronous interaction had a stronger statistical impact on the overall course grades. Meanwhile, a study on pharmacists' perceptions of synchronous and asynchronous distance learning was conducted by Buxton, (2014). A total of 82 students were enrolled in the study, with one group doing synchronous online learning and the other doing asynchronous online learning. Participants in the asynchronous course were delighted and gave good scores to their learning experiences, according to the study. Berry, (2017) stated in the Ph.D thesis which evaluated educational outcome results from online Algebra 1 courses to see if there was a significant difference between synchronous and asynchronous students for end-of-course grades. According to the findings, synchronous students had slightly lower end-of-course grades and standardized test scores than asynchronous students. 
Special Issue: Foundation Program Education Post-Covid-19: Issues and Opportunities There may not be enough relevant literature for foundation students enrolled in a Mathematics course to compare their preferences for asynchronous and synchronous e-learning resources employing different learning styles. According to Yadav (2017), mathematics is divided into two branches: pure mathematics and applied mathematics. He claims that, rather than using knowledge in practical ways, pure mathematics is concerned with increasing individual's understanding of the subject, i.e., theoretical learning applied mathematics has an impact on the use of pure mathematics knowledge. It is merely hypothetical, not realistic. Yadav, (2017)

Due to MCO, which took effect on March 18, 2020, lecturers at UMS could conduct asynchronous and synchronous classes. However, the existing traditional form of learning demonstrates that face-to-face communication between students and instructors or classmates is still necessary to avoid misconceptions in knowledge delivery and comprehension. It also makes it easier for them to share their thoughts and opinions. The goal of this study was to find out students' perceptions about synchronous and asynchronous e-learning tools at the foundation education level. It also sought to recognize the differences in male and female students' utilization of online resources at the foundation education level. In view of student observations and learning assessments, it is critical to comprehend how students perceive learning in various circumstances. (Greller \& Drachsler, 2012)

\section{Asynchronous E-Learning}

Asynchronous e-learning is a stand-alone method of e-learning that is designed for self-study and in which the students and teachers collaborate independently (Hun \& Morris, 2009). Learners in asynchronous environments have immediate access to content like articles, audio/video lectures, presentations, and handouts. In terms of invigorating students' interests, asynchronous approach allows students to save and download lecture materials, as well as watch the contents at their own paces, whether online or offline (Raymond et al., 2016). Asynchronous e-learning approaches, according to Sims \& Dobbs, (2002) and Garrison, (2003), can provide a rich cognitive presence, capable of supporting effective and higher-order thinking.

\section{Synchronous E-Learning}

Synchronous cooperation motivates people to react and considers group activity, such as brainstorming and exchanging ideas (Hrastinski, 2008). This e-learning paradigm features a structure that allows teachers and students to collaborate. This e-learning paradigm features a structure that allows teachers and students to collaborate. Instructor-learner and learner-learner contact are both involved in synchronous e-learning. Synchronous e-learning is real-time, continuing, and regularly scheduled, with a focus on learning and collaboration (Shahabadi \& Uplane, 2015). Synchronous communication allows for quicker data transfer rates than asynchronous communication because the lecturers and students are in the same virtual space at the same time. (Mabrito, 2006)

\section{Objectives of The Study}

The following objectives carried out the study:

1. To investigate the students' attitudes toward using synchronous e-learning practices in the foundation study.

2. To investigate the students' attitudes toward using asynchronous e-learning practices in the foundation study. 
Special Issue: Foundation Program Education Post-Covid-19: Issues and Opportunities 3. Identify the differences in the perspectives of male and female students on synchronous and asynchronous e-learning activities in the foundation study.

4. Identify the differences in internet usage between male and female students in the foundation study.

\section{Hypotheses of The Study}

The purpose of the study was to test the following hypotheses:

1. The mean scores for the preference of synchronous e-learning practices differ significantly between male and female students.

2. The mean scores for the preference of asynchronous e-learning practices differ significantly between male and female students.

3. There is no difference in male and female students' mean scores for the usage of the internet in hours per day.

4. There is no difference in the mean scores for male and female students for the preference of blended learning activities.

\section{Methodology}

\section{Sampling and sample}

During the COVID-19 crisis, OL-sync and OL-async approaches were popular as teaching methods. The participants of this study were students enrolled in Mathematics courses, offered in UMS foundation studies in the semester 1 session 2021/2022. Off-campus students took the course online. The requirements are including the students' internet connection and topics given in a particular week. The total sample size for the study consisted of 311 students for three programs such as Science (248), Information Technology (39), and Agriscience (24). The authors selected all the foundation students of these programs and sent the e-questionnaires to all of them. The students filled up the e-questionnaires in each of the online circumstances including synchronous and asynchronous e-learning environment. In this investigation, Google Meet or Webex Cisco were used for OL-sync, whereas the Smartv3ums and Youtube platforms were employed for OL-async.

\section{Data Collection Tools}

\section{Instrument}

The researchers designed an instrument that can be used to determine the preferred or most commonly used mode of learning among e-learners in an online learning environment. The instrument focuses on the measure used by admitting students in OL-sync and OL-async elearning classes to determine learning environment preference. This questionnaire contains 16 questions about the OL-sync and OL-async e-learning classroom (e-classroom), perceptions, preferred e-facilities, and associated synchronous or asynchronous learning modes. The authors used survey tools to get responses from students in this manner. After collecting the primary data, the following research questions were given preference by the authors: Question 1: What is the students' perception about the various asynchronous and synchronous communication mechanisms that are employed in e-learning environments? Question 2: Does the use of asynchronous communication support or hinder learning? Question 3: Can an asynchronous model be completely replaced by synchronous model, or blended learning is more effective? Questions were purposefully and indirectly posed to virtual students about their preference types and time spent per day on online learning. Likert scale is used and each question is rated Copyright (C) GLOBAL ACADEMIC EXCELLENCE (M) SDN BHD - All rights reserved 
Special Issue: Foundation Program Education Post-Covid-19: Issues and Opportunities on five-point scale of distress (1-5) ranging from "Strongly Disagreed" to "Strongly Agreed". (Xie, H., Liu, W., \& Bhairma, 2018)

\section{Implementation of OL-sync}

Google Meet or Webex Cisco

Google Meet or Webex Cisco are the chosen apps for the face-to-face method, where instructors can interact with students in real-time. During a spontaneous question and answer session, lecturers can read the students' facial expressions to gauge their comprehension level. This app, however, burdens students because it consumes a lot of data.

\section{Implementation of OL-async}

\section{Smartv3ums Platform or Learning Management Systems (LMSs)}

Smartv3ums' platform is more user-friendly and lightweight than Google Meet or Cisco Webex. This platform has systematic assignment management and uploading videos. Lecturers can share learning materials in various types of files through the Smartv3ums platform that has been integrated into the YouTube channel. Smartv3ums supports a wide range of file types that can be uploaded and transmitted, including text, images, videos, links, and many others. Students can comment, share ideas or discuss on the page by interacting with one another.

\section{Data Analysis}

For data analysis, Microsoft Excel was used. The mean difference in male and female students' perceptions of synchronous and asynchronous e-learning activities is analyzed. Blended elearning and usage of e-learning resources were identified through an independent sample ttest. Descriptive statistics were used to identify student responses regarding their preferences in various programs of study. For t-test analysis, the significance levels were set at $p<0.05$.

\section{Results and Discussions}

The descriptive statistics and data analysis results will be presented in this section.

Table 1: Descriptive Statistics for The Study's Variables

\begin{tabular}{llll}
\hline Variable & Factors & Frequency & Total \\
\hline Gender & Male & 107 & 311 \\
& Female & 201 & \\
Program & Science & 248 & 311 \\
& Information Technology & 39 & \\
& Agriscience & 24 &
\end{tabular}


GENDER

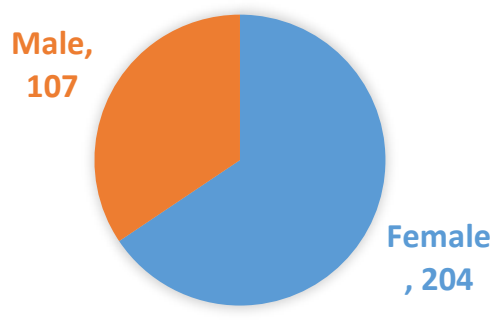

Figure 1: Gender of Foundation Level Students

Table 1, Fig. 1, and Fig. 2 represent descriptive statistics of the study.

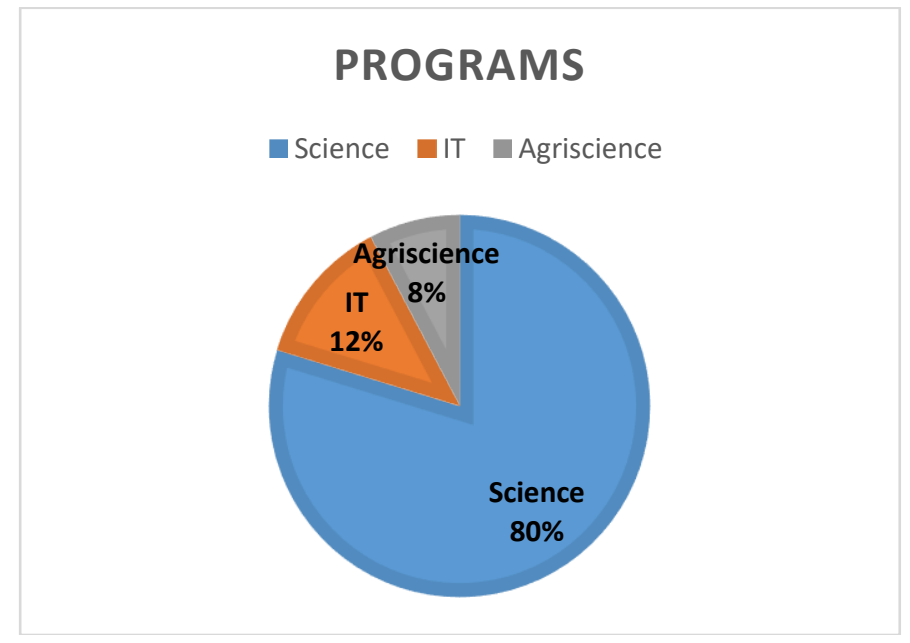

Figure 2: Foundation Level Students Based on Different Programs

Table 2: t-test to Determine The Mean Difference Between Male and Female Students' Preferences for Synchronous and Asynchronous E-Learning Resources, Blended E-

Learning, and Internet Use in Hours Per Day

\begin{tabular}{|c|c|c|c|c|c|c|c|}
\hline Variables & Gender & $\mathbf{N}$ & Mean & SD & df & t-value & Sig. \\
\hline \multirow{2}{*}{ Synchronous } & Female & 202 & 3.22 & 0.763 & 306 & 0.45 & 0.07 \\
\cline { 2 - 6 } & Male & 106 & 3.36 & 0.807 & & & \\
\hline \multirow{2}{*}{ Asynchronous } & Female & 203 & 4.04 & 0.832 & 307 & 1.76 & 0.04 \\
\cline { 2 - 6 } & Male & 106 & 3.87 & 0.782 & & & \\
\hline \multirow{2}{*}{ Blended learning } & Female & 202 & 3.88 & 0.753 & 305 & 1.0 & 0.46 \\
\cline { 2 - 6 } & Male & 105 & 3.89 & 0.858 & & & \\
\hline \multirow{2}{*}{$\begin{array}{c}\text { Use of internet in } \\
\text { Hours per day }\end{array}$} & Female & 203 & 4.90 & 1.00 & 307 & 0.65 & 0.25 \\
\cline { 2 - 8 } & Male & 106 & 4.82 & 1.08 & & & \\
\hline
\end{tabular}

Table 2 shows the results of "One-Sample t-tests" to determine the mean difference in male and female students' responses for the preference of synchronous and asynchronous e-learning resources, blended learning, and male and female students' internet usage. There was no 
Special Issue: Foundation Program Education Post-Covid-19: Issues and Opportunities significant difference in mean student scores for the preference of synchronous e-learning resources, according to the findings. Mean score of male students $(M=3.36, S D=0.807)$ was slightly greater than female students $(M=3.22, S D=0.763), t(306)=0.45, p>0.05$. There was a significant difference in mean student scores for the preference of asynchronous elearning resources. Mean score of female students $(M=4.04, S D=0.832)$ was greater than male students $(M=3.87, S D=0.782), t(307)=1.76, p<0.05$. In contrast, there was no statistically significant difference in the mean scores of students' responses for the preference of blended learning. Mean score of male students $(M=3.89, S D=0.858)$ was almost same with female students $(M=3.88, S D=0.753), t(305)=1.0, p=0.46$. It is also clear that there was no significant difference in the mean scores of students' responses to internet usage in hours per day. Mean score of male students $(M=4.90, S D=1.00)$ was slightly greater than female students $(M=4.82, S D=1.08), t(307)=0.65, p=0.25$. As a result, the research hypotheses predicting a significant difference in mean scores between male and female students for the preference of synchronous e-learning activities are rejected. On the other hand, the hypothesis that there is a significant difference in mean scores between male and female students in terms of the preference of asynchronous e-learning activities is accepted. While the research hypothesis that there is no significant mean difference in internet use by male and female students at the higher education level, as well as the hypothesis that there is no difference in mean scores of male and female students for the preference of blended learning activities at the higher education level, are accepted. All of these findings led to the conclusion that either male or female students' responses show that they found both synchronous and blended learning resources to be equally effective, while both (male and female) use the internet for nearly the same number of hours per day. Despite this, female students' responses indicate that they found asynchronous to be more effective than male students.

\begin{tabular}{|c|c|c|c|c|}
\hline Variables & Program of Study & $\mathbf{N}$ & Mean & Std. Deviation \\
\hline \multirow[t]{4}{*}{ Synchronous } & Science & 248 & 2.96 & 0.820 \\
\hline & Information & 39 & 3.18 & 0.756 \\
\hline & Technology & & & \\
\hline & Agriscience & 24 & 3.00 & 0.816 \\
\hline \multirow[t]{4}{*}{ Asynchronous } & Science & 248 & 4.01 & 0.834 \\
\hline & Information & 39 & 3.92 & 0.703 \\
\hline & Technology & & & \\
\hline & Agriscience & 24 & 3.75 & 0.794 \\
\hline \multirow{4}{*}{$\begin{array}{l}\text { Blend of the two } \\
\text { (Synchronous and } \\
\text { Asynchronous) }\end{array}$} & Science & 248 & 3.88 & 0.778 \\
\hline & Information & 39 & 4.08 & 0.774 \\
\hline & Technology & & & \\
\hline & Agriscience & 24 & 3.50 & 0.834 \\
\hline
\end{tabular}

Table 3 displays the descriptive statistics of responses to the preference in synchronous and asynchronous e-learning resources by students enrolled in different programs in the foundation education level in UMS. According to the table, the mean score $(\mathrm{M}=3.18, \mathrm{SD}=0.756)$ of students enrolled in IT for the preference of synchronous e-learning resources was higher than other programs. While the mean score of students' responses in Agriscience was slightly less than the mean score of IT. Whereas, mean scores of students' responses $(\mathrm{M}=2.96, \mathrm{SD}=0.820)$ 


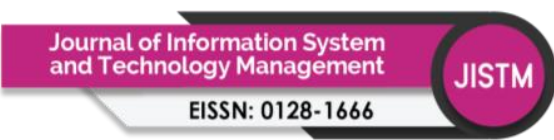

Volume 6 Issue 23 (November 2021) PP. 108-117

DOI: 10.35631/JISTM.623009

Special Issue: Foundation Program Education Post-Covid-19: Issues and Opportunities in the Science program was the lowest in the programs. The following section demonstrates that students enrolled in the Science program had a higher mean score $(\mathrm{M}=4.01, \mathrm{SD}=0.834)$ for the preference of asynchronous e-learning resources than students enrolled in other programs of study. While the mean of students' responses in the Agriscience program $(\mathrm{M}=$ $3.75, \mathrm{SD}=0.794$ ) was very low for the preference of asynchronous e-learning resources than the other programs.

Table 4 presents the descriptive statistics of students' responses to the statements given in the questionnaire. A total of $84.8 \%$ and $84.4 \%$ of participants were aware of synchronous and asynchronous modes of e-learning respectively. Mean score $(\mathrm{M}=3.66, \mathrm{SD}=0.77)$ for students' responses to the statement that asynchronous communication process facilitates learning process because it is flexible while mean score $(\mathrm{M}=3.27, \mathrm{SD}=0.778)$ for students' responses to the statement that synchronous learning is not adaptable regarding time. Mean score $(\mathrm{M}=$ 3.37, $\mathrm{SD}=0.975$ ) for students' responses to the statement internet data usage for synchronous study rather than asynchronous study. A higher mean score $(\mathrm{M}=3.86, \mathrm{SD}=0.798)$ for the statement that students feel more convenience using asynchronous communication tools than synchronous communication tools because they could access video lectures anytime. Whereas students' responded to the statement that students feel convenience using synchronous communication tools in comparison to asynchronous communication tools as they could ask questions to lecturers promptly for mean score $(\mathrm{M}=3.45, \mathrm{SD}=0.778)$. In addition, many students found it more effective to learn through both e-learning resources, proving that a blend of the two (Synchronous and Asynchronous) is better in facilitating learning for the mean score $(\mathrm{M}=3.87, \mathrm{SD}=0.790)$.

Table 4: Descriptive Statistics of Students' Responses

\begin{tabular}{|c|c|c|c|}
\hline & Statement & Mean & SD \\
\hline 1 & Do you know what is synchronous mode of learning? & 4.24 & 0.852 \\
\hline 2 & Do you know what is asynchronous mode of learning? & 4.22 & 0.848 \\
\hline 3 & $\begin{array}{l}\text { Is it true that asynchronous communication facilitates learning } \\
\text { since it is flexible? }\end{array}$ & 3.66 & 0.770 \\
\hline 4 & $\begin{array}{l}\text { Synchronous learning is not time adaptive since students must set } \\
\text { up a certain time slot with a specific goal in order to attend a live } \\
\text { teaching session or an online course sequentially. }\end{array}$ & 3.27 & 0.778 \\
\hline 5 & $\begin{array}{l}\text { When I study synchronously rather than asynchronously, I utilize } \\
\text { a lot of internet bandwidth. }\end{array}$ & 3.37 & 0.975 \\
\hline 6 & $\begin{array}{l}\text { In comparison to synchronous communicational technologies, } \\
\text { students felt more comfortable utilizing asynchronous } \\
\text { communicational tools because they could access lecture videos } \\
\text { anytime. }\end{array}$ & 3.86 & 0.798 \\
\hline 7 & $\begin{array}{l}\text { In comparison to asynchronous communication technologies, } \\
\text { students felt more comfortable utilizing synchronous } \\
\text { communication tools because they could ask lecturers questions } \\
\text { promptly. }\end{array}$ & 3.45 & 0.778 \\
\hline 8 & $\begin{array}{l}\text { I think a blend of the two (Synchronous and Asynchronous) is } \\
\text { better in facilitating learning }\end{array}$ & & 0.790 \\
\hline
\end{tabular}




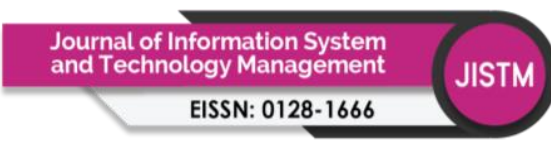

Volume 6 Issue 23 (November 2021) PP. 108-117

DOI: 10.35631/JISTM.623009

Special Issue: Foundation Program Education Post-Covid-19: Issues and Opportunities The responses are summarised in the following items:

1. Students seem to be convenient to use asynchronous communication tools rather than synchronous communication tools because they could access those anytime. Furthermore, students agreed that a blend of the two (Synchronous and Asynchronous) is better in facilitating learning. However, they believe that synchronous communication tools are vital because they can ask lecturers questions promptly, which helps them to learn better.

2. Asynchronous mode is advantageous for students who are doubtful or shy. It may be unsettling to participate in computer-mediated discussions.

3. Students also think a blend of the two (Synchronous and Asynchronous) is better in facilitating learning.

4. Since synchronous and asynchronous e-learning approaches have advantages and disadvantages, blended learning of synchronous and asynchronous models should be appropriate for foundation-level students at UMS in learning Mathematics.

\section{Conclusions}

The goal of this study is to determine students' perceptions of online learning and to recognize which modes of e-learning environments and communication tools are best suited to support and enhance students' learning. This descriptive study used a survey as the methodology and a structured questionnaire as the data collection instrument. The results of this research are based on 311 students for three programs of foundation study in UMS. From the results, a blend of synchronous and asynchronous modes and asynchronous approaches are more desirable for students enrolled during the pandemic than used solely on synchronous approach. The observation of student perceptions of asynchronous and synchronous learning activities assists researchers in developing a deeper understanding of the relationship between the existing instructional design's contents, pedagogies, technology, and context (Koehler \& Mishra, 2005). Students can build their reactions in asynchronous mode by thinking, considering, and analyzing. On the other hand, synchronous sessions can put additional strain on the ability to react promptly. They can spot the difference between levels of preparation. As a result, for significant e-learning, blended e-learning should have a scaffold over synchronous or asynchronous e-learning solely for deep learning among students.

\section{References}

Berry, S. (2017). Educational Outcomes of Synchronous and Asynchronous High School Students: A Quantitative Causal-Comparative Study of Online Algebra 1. In Doctoral dissertation. Northeastern University.

Buxton, E. C. (2014). Pharmacists' perception of synchronous versus asynchronous distance learning for continuing education programs. American Journal of Pharmaceutical Education, 78(1), 1-7. https://doi.org/10.5688/ajpe7818

Duncan, K., Kenworthy, A., \& McNamara, R. (2012). The Effect of Synchronous and Asynchronous Participation on Students' Performance in Online Accounting Courses. Accounting Education, 21(4), 431-449. https://doi.org/10.1080/09639284.2012.673387

Garrison, D. R. (2003). Cognitive presence for effective asynchronous online learning: the role of reflective inquiry, self-direction, and metacognition. Elements of Quality Online Education: Practice and Direction, 4(1), 47-58.

Hrastinski, S. (2008). Asynchronous and synchronous e-learning. Educause Quarterly, 31(4), $51-55$

Copyright $\odot$ GLOBAL ACADEMIC EXCELLENCE (M) SDN BHD - All rights reserved 
Special Issue: Foundation Program Education Post-Covid-19: Issues and Opportunities

Hun, L. D., \& Morris, M. L. (2009). Learner and instructional factors influencing learning outcomes within a blended learning environment. Educational Technology and Society, 12(4), 282-293.

Koehler, M. J., \& Mishra, P. (2005). What happens when teachers design educational technology? The development of Technological Pedagogical Content Knowledge. Journal of Educational Computing Research, 32(2), 131-152.

Libasin, Z., Azudin, A. R., Idris, N. A., Abdul, M. S., Libasin, Z., Azudin, A. R., \& Idris, N. A. (2021). Comparison of Students' Academic Performance in Mathematics Course with Synchronous and Asynchronous Online Learning Environments during COVID19 Crisis. Comparison of Students 'Academic Performance in Mathematics Course with Synchronous and Asynchronous. 1(2), 492-501. https://doi.org/10.6007/IJARPED/v10-i2/10131

Mabrito, M. (2006). A Study of Synchronous Versus Asynchronous Collaboration in an Online Business Writing Class. International Journal of Phytoremediation, 21(1), 93-107. https://doi.org/10.1207/s15389286ajde2002_4

Raymond, E., Atsumbe, B., Okwori, R., \& Jebba, A. M. (2016). Comparative Effects of the Synchronous and the Asynchronous Instructional Approaches Concerning the Students' Achievements and Interests in Electrical Engineering at the Niger State College of Education. International Journal of Engineering Pedagogy (IJEP), 6(3), 4. https://doi.org/10.3991/ijep.v6i3.5302

Shahabadi, M. M., \& Uplane, M. (2015). Synchronous and Asynchronous e-learning Styles and Academic Performance of e-learners. Procedia - Social and Behavioral Sciences, 176, 129-138. https://doi.org/10.1016/j.sbspro.2015.01.453

Sims, R., \& Dobbs, G. (2002). Enhancing Quality in Online Learning : Scaffolding Planning and Design Through Proactive Evaluation. Distance Education, 23(2), 135-148. https://doi.org/10.1080/0158791

Singh, V., \& Thurman, A. (2019). How Many Ways Can We Define Online Learning? A Systematic Literature Review of Definitions of Online Learning (1988-2018). American Journal of Distance Education, 33(4), 289-306. https://doi.org/10.1080/08923647.2019.1663082

Wolfgang Greller \& Drachsler, H. (2012). Translating Learning into Numbers: A Generic Framework for Learning Analytics. Journal Of Educational Technology \& Society, 15(3), 42-57. http://www.ifets.info/journals/15_3/ets_15_3.pdf

Xie, H., Liu, W., \& Bhairma, J. (2018). Analysis of synchronous and asynchronous e-learning environments. 3rd Joint International Information Technology, Mechanical and Electronic Engineering Conference (JIMEC 2018), 270-274.

Yadav, D. K. (2017). Exact definition of Mathematics. International Research Journal of Mathemathics, Engineering and IT, 4(1), 34-42. 